\title{
Disease Features Associated with a low Disease Impact in Patients with Psoriatic Arthritis: Results of a Cross-Sectional Multicenter Study
}

Rubén Queiro ( $\nabla$ rubenque7@yahoo.es)

Hospital Universitario Central de Asturias https://orcid.org/0000-0002-8418-7145

Juan D Cañete

Hospital universitario clinic

María Montoro

Pfizer Spain

Susana Gómez

Pfizer Spain

Ana Cábez

Pfizer,Spain

Research article

Keywords: psoriatic arthritis, PSAID, MDA, DAPSA, remission, impact of disease

Posted Date: March 12th, 2020

DOI: https://doi.org/10.21203/rs.2.19994/v2

License: (c) (i) This work is licensed under a Creative Commons Attribution 4.0 International License.

Read Full License

Version of Record: A version of this preprint was published at Arthritis Research \& Therapy on April 15th, 2020. See the published version at https://doi.org/10.1186/s13075-020-02168-1. 


\section{Abstract}

Background Patient reported outcomes measures, such as those provided by the the Psoriatic Arthritis Impact of Disease (PSAID) questionnaire, have been found to be a reliable indicator of change during treatment, predictive of long-term outcomes, and the impact of psoriatic arthritis (PsA) on patients' lives. The objective of the study was to describe demographic and clinical characteristics of PsA patients with a low disease impact and to analyze predictive factors for that state.

Methods Post-hoc analysis of a cross-sectional multicenter study that included 223 consecutive patients. The Psoriatic Arthritis Impact of Disease (PsAID) questionnaire was used to estimate disease impact. Patients with a PsAID < 4 were considered in low disease impact. Minimal Disease Activity (MDA) response and the Health Assessment Questionnaire (HAQ) were also assessed. The degree of agreement between the different outcomes was addressed by Cohen's kappa index.

Results One hundred and twenty-two (54.7\%) patients reached a PsAID $<4$. Among them, $52.0 \%$ and $68.0 \%$ presented articular or skin remission, respectively. Almost $75 \%$ of patients were in MDA state and $85.2 \%$ presented a low disability state according to the HAQ. A moderate concordance between HAQ $\leq$ 0.5 and PsAID $<4$ ( $k=0.53)$, fair between MDA and PsAID $<4 \quad(k=0.36)$, and moderate between DAPSA remission and PsAID $<4(k=0.46)$, was observed. Multivariate logistic regression analysis showed that patients with distal interphalangeal joint (DIP) disease (OR 0.40, 95\% Cl: $0.20-0.79, p=0.009$ ), family history of PsA (OR 0.25, 95\% Cl: 0.09-0.72, $\mathrm{p}=0.010)$, and higher C-reactive protein (OR $0.92,95 \% \mathrm{Cl}$ : $0.85-$ $0.99, p=0.036$ ) were significantly less likely to reach a PSAID $<4$.

Conclusions There is certain discrepancy between disease activity measures and a low impact of disease in PsA. Clinical features (DIP joint involvement), biologic activity, and genetic factors (familial history), seem to be associated with lower odds of reaching a low disease impact.

\section{Background}

The Outcome Measures in Rheumatology (OMERACT) update core set for PsA evaluation comprises the domains: musculoskeletal disease activity, skin disease activity, fatigue, pain, patient global assessment (PGA), physical function, health related quality of life (QoL) and systemic inflammation [4]. Prior literature review indicated that pain, PGA, health assessment questionnaire (HAQ) were frequently measured, however other measures of how the patients feels or sleep were rarely reported [5].

Gossec et al. developed and validated the Psoriatic Arthritis Impact of Disease (PsAID) questionnaire, which was made with extensive patient input so better relates to their concerns. PsAID can be used to calculate a score reflecting the impact of PsA on patients' lives [6]. The PsAID questionnaire assesses 12 physical and psychological domains, ranging from pain or physical activity to anxiety or embarrassment. The PsAID is an effective QoL measure for PsA patients [3]. 
Patient reported outcomes measures (PROMs), such as those provided by the PsAID questionnaire, have been found to be a reliable indicator of change during treatment, predictive of long-term outcomes, and the impact of PsA on patients' lives [5-7]. Discrepancy between patient's and physician's ratings of general health status has been demonstrated [8-10]. In PsA, factors associated with discordance were psychological rather than physical and were more frequent in patients in remission [10]. The consequence of such a discordant viewpoint with regard to disease activity is that decisions are often prone to not being shared between patients and physicians [8-10]. The patients' own perspectives of their health status may therefore be an important additional measure to assess the level of disease activity and for clinical decision-making.

The aims of the present study were to describe demographic and clinical characteristics of PsA patients with an acceptable symptoms state (PsAID score $<4$ ), to analyze predictive factors for PsAID $<4$, and the association between that state and other disease activity outcomes.

\section{Patients And Methods}

This was a post-hoc analysis of data from an observational, multicenter, cross-sectional study carried out at twenty-five rheumatology outpatient clinics in the whole of Spain [11].

The study included outpatients of both genders over 18 years of age, diagnosed with PsA according to the Classification for Psoriatic Arthritis (CASPAR) criteria [12], with at least one year of disease duration, with hand and foot radiological tests carried out during the six months prior to the study visit, and under treatment with biological and/or conventional synthetic Disease-Modifying Anti-rheumatic Drugs (csDMARDs).

Data were collected between May 2014 and February 2015 at the single study visit. Patient data collection included demographics and clinical characteristics. Patients completed the self-reported PsAID questionnaire. In addition, MDA state [13], and the HAQ were assessed.

The PsAID questionnaire reflects the impact of PsA from the patients' perspective [6]. It is comprised of 12 physical and psychological domains. Each domain is rated from 0 to 10 with a different weighting. Total score is divided by 20. The final score has a range from 0 (best status) to 10 (worst status) with a cutoff of 4 . PsAID score 4 identified a patient-acceptable symptom state (PASS), also regarded as a low disease impact [6].

Patients were considered in MDA when they met $\geq 5$ of the following criteria: tender joint count $\leq 1$, swollen joint count $\leq 1$, Psoriasis Area and Severity Index (PASI) score $\leq 1$ or body surface area $\leq 3 \%$, patient pain visual analog scale (VAS) score $\leq 15$, patient global disease activity VAS score $\leq 20, \mathrm{HAQ}$ score $\leq 0.5$ and tender entheseal points $\leq 1$ [13].

Disease Activity in PSoriatic Arthritis (DAPSA) score was calculated by adding the number of tender and swollen joints, VAS pain, patient-reported global assessment (PGA), and C-reactive protein (CRP). The 
CDAPSA was calculated without the contribution of CRP. DAPSA and CDAPSA score $\leq 4$ identified clinical remissions [14]. Remission was also evaluated according to the vision of the evaluating physicians (specific question yes/no).

\section{Statistical methodology}

A descriptive statistical analysis of all the variables was performed, including central tendency and dispersion measures for continuous variables, and absolute and relative frequencies for categorical variables. Student's t-test, Mann-Whitney-U test or Kruskall Wallis $\mathrm{H}$ test were used to compare quantitative variables and Pearson's chi-square or Fisher's exact tests for qualitative variables.

Concordance was assessed using Cohen's карра $(\mathrm{k})$. Univariate and multivariate models were carried out to identify factors independently associated with a PASS status. Tests were two-tailed with a significance level of $5 \%$. Data were analyzed using SPSS V19.0 statistical software.

\section{Results}

A total of 122 patients (54.7\%) with a PsAID score <4 (PASS) were included in the present post-hoc analysis. Demographic and clinical characteristics of the study population are shown in Table 1. More than half of patients were men (57.4\%) with a mean (SD) age of 54.5 (12.7) years. Mean disease duration was 9.6 (7.9) years and the musculoskeletal symptoms onset occurred nearly 10 years after the skin symptoms appeared. Seventy-three patients (59.8\%) were employed, while $2.5 \%$ had full disability to work due to PsA. More than half (57.4\%) suffered from some kind of comorbidity.. Regarding PsA condition, most patients were diagnosed with peripheral disease. . Erosions in hand or feet were found in approximately $30 \%$ of patients (Table 1 ). 
Table 1. Demographic and clinical characteristics of PsAID $<4$ patients

\begin{tabular}{|c|c|c|c|}
\hline & $\begin{array}{c}\text { PsAID <4 } \\
N(122)\end{array}$ & $\begin{array}{c}\text { PsAID } \geq 4 \\
N(101)\end{array}$ & $P$ value \\
\hline $2, n(\%)$ & 70 (57.4) & $51(50.5)$ & NS \\
\hline mean (SD), yr & $54.5(12.7)$ & $51.7(12.7)$ & NS \\
\hline , mean $(\mathrm{SD})\left(\mathrm{kg} / \mathrm{m}^{2}\right)$ & $27.1(3.9)$ & $26.3(4.8)$ & NS \\
\hline ' (mg/L), mean (SD) & $2.8(3.3)$ & $4.6(8.4)$ & $<0.05$ \\
\hline ıorbidities, n (\%) & $70(57.4)$ & $43(57.4)$ & NS \\
\hline Jyslipemia & $40(32.8)$ & $29(28.7)$ & NS \\
\hline IBP & $33(27.0)$ & $27(26.7)$ & NS \\
\hline besity & $30(24.6)$ & $16(15.8)$ & NS \\
\hline IM & $12(9.8)$ & $9(8.9)$ & NS \\
\hline \multicolumn{4}{|l|}{ clinical pattern, n (\%) } \\
\hline xial & $3(2.5)$ & $4(4.0)$ & \\
\hline 'eripheral & 107 (87.7) & 79 (78.2) & \\
\hline Aixed & $12(9.8)$ & $18(17.8)$ & \\
\hline tylitis, & $64(52.5)$ & $47(46.5)$ & NS \\
\hline \multirow[t]{2}{*}{ Iesitis } & $45(36.9)$ & $35(34.7)$ & NS \\
\hline & $45(36.9)$ & $48(47.5)$ & NS \\
\hline \multicolumn{4}{|l|}{ ilial history, n (\%) } \\
\hline 'soriasis & $60(49.2)$ & $51(50.5)$ & NS \\
\hline 'sA & $11(9.0)$ & $16(15.8)$ & NS \\
\hline nkylosing spondylitis & $2(1.6)$ & $0(0.0)$ & NS \\
\hline duration, mean (SD), yrs. & $9.6(7.9)$ & $9.7(7.7)$ & NS \\
\hline I symptoms duration, mean (SD), yrs. & $21.6(14.5)$ & $22.9(15.0)$ & NS \\
\hline :ular symptoms duration, mean (SD), yrs. & $11.9(8.7)$ & $12.6(10.0)$ & NS \\
\hline \multicolumn{4}{|l|}{ iologic findings } \\
\hline :rosions in hands, n (\%) & $40(32.8)$ & $43(42.6)$ & NS \\
\hline rosions in feet, $\mathrm{n}(\%)$ & $33(27.0)$ & $32(31.7)$ & NS \\
\hline
\end{tabular}

: Body mass Index. CRP: C-reactive Protein HBP: High blood pressure; DIP: distal interphalangeal joint disease. DM: Diabetes itus; SD: Standard deviation; NS: Non-significant

There were no differences in the exposure to systemic drugs among patients who achieved a PASS status compared to those who did not reach that situation. $75.4 \%$ of the subjects in the PASS state received conventional DMARDs compared to $76.2 \%$ of the non-PASS subjects. The median exposure to conventional DMARDs was 50.1 months (62.1-92.9) in the PASS subjects versus 53.9 months (52.2-84.5) 
in the non-PASS ( $p$ non-significant). With regard to biological therapies (mainly anti-TNF-alpha), $46 \%$ of PASS subjects received these agents compared to $52.5 \%$ of non-PASS ( $\mathrm{p}$ non-significant). The median exposure to biologic therapy was 41.2 months (40.1-59.4) in the PASS subjects versus 35 months (31.850.9) in the non-PASS subjects ( $p$ non-significant). However, there were statistically significant differences in the exposure to systemic corticosteroids, so that $24 \%$ of non-PASS patients received these drugs compared to $12 \%$ of PASS patients, $p=0.025$.

Clinical remission characteristics of the study population are shown in Table 2. According to physician criteria, $52.0 \%$ and $68.0 \%$ of patients presented articular or skin remission respectively. MDA response was achieved by $74.5 \%$ of patients in PASS state. The most common MDA active domains were patient pain VAS $\leq 1.5$ and global disease activity VAS score $\leq 20$ achieved only by $53.4 \%$ and $55.7 \%$ of PsAID $<4$ patients, respectively (Table 2 ). The majority (85.2\%) of patients presented a low disability state according to HAQ [mean (SD) total score $0.2(0.3)$ ]

A moderate concordance between $\mathrm{HAQ} \leq 0.5$ and PsAID $<4$ (kappa[CI $\left.{ }_{95 \%}\right] \quad 0.53$ [0.42-0.64]) and fair between MDA and PsAID <4 (kappa [CI $\left.{ }_{95 \%}\right] 0.3594$ [0,2393-0,4795] ) was observed. Concordance between PsAID $<4$ and skin $\left(\mathrm{kappa} \mathrm{CI}_{95 \%}\right] 0.28$ [0.15-0.41]) or articular $\left(\mathrm{kappa} \mathrm{CI}_{95 \%}\right] 0.18$ [0.05-0.31] ) remission was considered poor. Kappa agreement between DAPSA remission and PsAID <4 was $0.46\left(\mathrm{CI}_{95 \%}\right.$ 0.340.58), (moderate agreement), while kappa value between CDAPSA remission and PsAID $<4$ was 0.58 $\left(\mathrm{CI}_{95 \%}\right.$ 0.47-0.70) (moderate agreement). 
le 2 Clinical remission characteristics of PsAID $<4$ patients

\begin{tabular}{|c|c|c|c|}
\hline & PsAID $<4$ & PsAID $\geq 4$ & $P$ value \\
\hline cular remission, $\mathrm{n}(\%)$ & $53(52.0)$ & $23(23.5)$ & $<0.001$ \\
\hline l remission, n (\%) & $83(68.0)$ & $51(50.5)$ & $<0.01$ \\
\hline \multicolumn{4}{|l|}{, n (\%) } \\
\hline snder joint count $\leq 1, \mathrm{n}(\%)$ & $91(74.6)$ & $53(52.5)$ & $<0,001$ \\
\hline vollen joint count $\leq 1, \mathrm{n}(\%)$ & $82(67.2)$ & $70(69.3)$ & NS \\
\hline tSI $\leq 1$ /Body Surface Area $\leq 3 \%, \mathrm{n}(\%)$ & 96 (79.3) & 78 (78.8) & NS \\
\hline ıtient pain VAS $\leq 1.5, \mathrm{n}(\%)$ & $63(53.4)$ & $7(7.1)$ & $<0,0001$ \\
\hline itient global disease activity VAS $\leq 20$, n (\%) & $68(55.7)$ & $28(27.7)$ & $<0,0001$ \\
\hline $\mathrm{AQ} \leq 0.5 \mathrm{n}(\%), \mathrm{n}(\%)$ & $104(85.2)$ & $33(32.7)$ & $<0,0001$ \\
\hline nder entheseal points $\leq 1$ & $99(81.8)$ & $80(79.2)$ & NS \\
\hline , mean (SD) & $1.2(3.8)$ & $1.8(3.2)$ & NS \\
\hline , mean (SD) & $0.2(0.3)$ & $0.9(0.6)$ & $<0.001$ \\
\hline
\end{tabular}

Jrding to physicians criteria; MDA; Minimal disease activity; PASI: Psoriasis Area and Severity Index; VAS: Il Analogue Scale HAQ; Health Assessment Questionnaire; PsAID: Psoriatic Arthritis Impact of Disease. onfidence intervals;

The variables associated with the PASS status in the univariate analysis $(p<0.10)$ were: age (OR 1.02), secondary education (OR 0.45), active workers (OR 2.23), retired (OR 2.72), smoking (OR 0.46), peripheral disease (OR 2.03), DIP involvement (OR 0.64), PsA family history (OR 0.52), coronary heart disease (OR 7.02), obesity (OR 1.73), CRP (OR 0.94), glucocorticoids (OR 0.45), and syndesmophytes (OR 0.44). Multivariate logistic regression analysis showed that patients with DIP joint involvement (odds ratio (OR) [95\%Cl], 0.40 [0.20-0.80]; p=0.009), family history of PsA (OR: 0.25 [0.09-0.72]; $p=0.010)$, and high CRP (OR: 0.92 [0.85-0.99]; $p=0.036$ ), were significantly less likely to reach a PsAID score < 4 . 


\section{Discussion}

In this post hoc analysis of the MAAPs study we verified that a high percentage (54.7\%) of patients with established PsA undergoing systemic therapies reached a low disease impact according to the PsAID questionnaire. However, joint or skin remission, defined by the evaluating physician, was not consistent with an acceptable symptomatic status. The agreement between other disease outcomes, such as the MDA response, or the HAQ, was fair or moderate, with respect to the PASS state.. On the other hand, the presence of DIP joint involvement, a higher CRP value at study visit, or a family history of PsA, diminished the odds of having reached a low impact of disease according to the PSAID.

In recent years, the rheumatology community has witnessed an intense search for sensitive and valid instruments that capture those clinical aspects related to disease activity, as well as those linked to the response to the scheduled treatments; along with other instruments, more focused on the experiences and perceptions lived by PsA patients [3-6, 15]. Despite this intense search, there is a remarkable mismatch between the results derived from the instruments for measuring disease activity (e.g., DAPSA), or those that assess the treatment objectives (e.g., MDA), and the PROMs (e.g., pain, fatigue, PsAID). Our results do not escape this decoupling, and in fact, the worst agreement was between the definition of remission by clinicians, and the PASS state according to the PSAID questionnaire. On the contrary, the best agreement was seen between cDAPSA remission and PASS. In this sense, our findings are quite consistent with those of the recently published ReFlap (Remission/Flare in PsA) study [16]. In ReFlap, adults with physician-confirmed PsA and $>2$ years of disease duration in 14 countries were included. Remission was defined as very low disease activity (VLDA), DAPSA $\leq 4$, and physician-perceived and patient-perceived remission. In this study, DAPSA-based remission/low disease activity (LDA) performed better than VLDA/MDA to detect patient defined remission or remission/LDA. Further, physician-perceived remission/LDA using a single question was frequent (67.6\%) but performed poorly against other definitions [16].

Which are the drivers of this discordance between patient-perceived remission, or low impact of disease, and physician-defined remission?. Discordance between patients and physicians may vary according to levels of disease activity. Possibly, in high disease activity, both patient and physician global assessments (PGA/ PhGA) will be unsatisfactory, whereas in LDA, patient and physician expectations may differ more frequently. In a recent study that included 460 patients (40.4\% undergoing treatment with biologic agents), discordance defined by $|\mathrm{PGA}-\mathrm{PhGA}| \geq 3$ of 10 , concerned 134 patients (29.1\%), and 115 patients (85.8\% of the patients with discordance) had PGA>PhGA. Higher fatigue, lower self-perceived coping, and impaired social participation, were independently associated with a higher difference PGA-PhGA [10] . Authors concluded that factors associated with discordance were psychological rather than physical domains of health. In our study, the most active components of the MDA response in subjects with high disease impact were pain, $P G A$, and $H A Q \geq 0.5$. This may reflect that pain (regardless of inflammatory activity), and physical dysfunction, are the main drivers of a state of high disease impact in these patients. In short, our findings are in line with previous studies that indicate a clear discrepancy between the results of the activity and impact outcomes of the disease represented in such indices as the 
PsAID. An instrument like the PsAID, which integrates not only physical but also psychosociological domains certainly comprises aspects that are not included in responses such the MDA or the DAPSA score, not even indirectly. It is therefore to be expected that concordance between the results of both tools only be moderate, as we observe in this study, both for MDA/PsAID and for DAPSA/PsAID.

This mismatch between the visions of doctors and patients is not a minor matter [17]. In another recent study, it was found that one third of patients in a clinically acceptable condition according to the evaluating physician, did not reach the MDA response, so that if a treat to target strategy had been applied, these patients should have received a therapeutic intensification [18]. Therefore, we need to balance the information from conventional activity measures, with those reflecting patient's perceptions, in order to make clinical and therapeutic decision making that conform to current disease management recommendations [19].

The nail plates and DIP joints are closely connected through a network of entheses, so that inflammation at these anchor points is the common immune connector to both domains of psoriatic disease [20]. Although the involvement of DIP joints is a well-known feature of PsA, little is known about the effect of this manifestation on QoL, the impact of the disease, or the achievement of treatment goals. A very recent study, showed that DIP disease decreased the odds of having reached the MDA response [21]. In our study, we have found a negative association between this manifestation and the PASS state; however, we did not detect any link between this trait and the MDA response. We can speculate on the fact that perhaps some of these patients could actually have DIP osteoarthritis (OA), which is usually associated with $O A$ at other locations, resulting in a worse functional status. However, one of the exclusion criteria of this study was the presence of a suspected or confirmed hand OA.

We also found that a positive PsA family history decreased the chances of reaching a state of low disease impact. In a classic study, HLA antigens B27, when DR7 was present, and DQw3, when DR7 was absent, predicted disease progression across all transitions, while HLA-B39 was associated with progression in early disease [22]. Disease progression, understood as progression of structural damage, is the main factor associated with a high HAQ (one of the most active components in our patients with high disease impact) [23]. This may allow us to speculate with some genetic background driving the factors associated to the perception of disease impact. However, the concept of disease impact is multifactorial, so this assumption does not go beyond being a mere hypothesis that requires adequately designed studies.

A recent subanalysis of the ReFlap study showed that high life impact (PsAID $\geq 4$ ) was associated with female gender, enthesitis, tender joints, and comorbidities [24]. Although in our study more men reached an MDA status, none of the factors found in the aforementioned Reflap study was associated with a high impact of disease in our population. Even more, some comorbidities (obesity, CHD) were positively associated with a low impact of disease in our series. Although obesity, and other elements of the metabolic syndrome, has been associated with worse QoL and worse therapeutic response in PsA, not all studies point in that direction $[25,26]$. 
Our study has the limitations of any cross-sectional study. It is therefore, an observation at a specific timepoint of a disease, such as PsA, which tends to a high phenotypic variability over time. In addition, the instrument chosen to measure disease activity (e.g., DAPSA) does not include important aspects of the disease (axial involvement, skin, enthesitis). On the other hand, the PsAID questionnaire surely captures many patient's perceptions, which go far beyond what can be included in a therapeutic objective such as MDA. Therefore, mismatch between these instruments is not unexpected.

\section{Conclusions}

The impact that PsA generates on patients' lives must be adequately addressed. In PsA, certain enthesitis-related characteristics (DIP disease), a high biologic activity (CRP), and some ill-defined genetic factors (family history), may contribute to a higher disease impact perception. This knowledge may help rheumatologists to better manage this condition.

\section{Abbreviations}

CASPAR: Classification for Psoriatic Arthritis

CRP: C-reactive protein

DIP: distal interphalangeal joint

DMARDs: Disease-Modifying Anti-Rheumatic Drugs

HAQ: the Health Assessment Questionnaire

MDA: Minimal Disease Activity

OMERACT: Outcome Measures in Rheumatology

PASI: Psoriasis Area and Severity Index

PGA: patient's global assessment

PROMs: Patient reported outcomes measures

PsAID: Psoriatic Arthritis Impact of Disease

PsA: Psoriatic arthritis

QoL: Quality of life

VAS: visual analog scale

\section{Declarations}




\section{Ethics approval and consent to participate}

All patients provided their informed written consent. In accordance with the Spanish recommendations, the study was approved by the Clinical Research Ethics Committee of La Fe Hospital [(ref number: FPNT07-14-EO (C)] and was conducted in accordance with the principles contained in the Declaration of Helsinki for studies in humans

\section{Consent for publication}

Not applicable

\section{Availability of data and materials}

The datasets used and/or analysed during the current study are available from the corresponding author on reasonable request

\section{Competing interests}

RQ has received fees for speaking and/or consulting from Abbvie, Celgene, Janssen, MSD, Novartis, Pfizer, and Lilly.

JDC has received fees for speaking and/or consulting from AbbVie, Boehringer, Bristol, Celgene, Janssen, MSD/Schering Plough, Novartis and Pfizer.

MM, SG, and AC are employees of Pfizer, S.L.U.

\section{Funding}

This study was funded by Pfizer, S.L.U.

\section{Authors' contributions}

$R Q, J D C, M M, S G$ and $A C$ have contributed sufficiently to the work for them to be named as authors are named. The manuscript has been read and approved by all the authors. The others investigators of the MAAPS Study are named in acknowledgements section

\section{Acknowledgements}

MAAPs (Minimal Activity in Psoriatic Arthritis) Study Group: Carlos Montilla (HU. Salamanca, Salamanca, Spain); Miguel Angel Abad (H. Virgen del Puerto, Plasencia, Spain); Juan Carlos Torre Alonso (H. Monte Naranco, Oviedo, Spain); Jose Andrés Román-Ivorra [Hospital Universitario (HU) La Fe, Valencia, Spain]; Jesús Sanz (HU Puerta de Hierro, Madrid, Spain); Juan Salvatierra (HU San Cecilio, Granada, Spain); Jaime Calvo-Alén (HU Sierrallana, Torrelavega, Spain); Agustín Sellas (Vall d'Hebron, Barcelona, Spain); Fernando José Rodriguez (Santa Lucia, Cartagena, Spain); Alberto Bermúdez (Virgen de la Arrixaca, Murcia, Spain); Manuel Romero (Complejo hospitalario Jaén, Spain); Manuel Riesco (Rheumatology H. 
Juan Ramón Jiménez, Huelva, Spain); Juan Carlos Cobeta (H. Royo Villanova, Zaragoza, Spain); Fermín Medina (H. Puerta del Mar, Cádiz, Spain); AngelAragón (H. Getafe, Madrid, Spain); M Luz García (HU Basurto, Bilbao, Spain); Ana Urruticoechea (H. Can Misses, Ibiza, Spain); Carlos González (HU Gregorio Marañón, Madrid, Spain); E. Judez (HU, Albacete, Spain); Beatriz González (HU Nta. Sra de la Candelaria, Tenerife, Spain); Pilar Fernández (HU 12 de Octubre, Madrid, Spain); Lucía Pantoja (H. del Bierzo, Leon, Spain); Rosa Morlá (H. Sant Pau y Sta. Tecla, Tarragona, Spain).

Medical writing support was provided by Esther Tapia and was funded by Pfizer.

\section{References}

1. Borman P, Toy GG, Babaoglu S, Bodur H, Ciliz D, Alli N. A comparative evaluation of quality of life and life satisfaction in patients with psoriatic and rheumatoid arthritis. Clin.Rheumatol. 2007;26(3):330334.

2. Haddad A, Thavaneswaran A, Ruiz-Arruza I, Pellett F, Chandran V, Cook RJ, Gladman DD. Minimal disease activity and anti-tumor necrosis factor therapy in psoriatic arthritis. Arthritis Care Res. (Hoboken.) 2015;67(6):842-847.

3. Johnson K, Ye JY, Chandran V, Gladman DD. A novel role for the psoriatic arhtirtis impact of disease (PsAID) questionnaire. Semin.Arthritis Rheum. 2019.

4. Orbai AM, de Wit M, Mease PJ, Callis Duffin K, Elmamoun M, Tillett W, Campbell W, FitzGerald O, Gladman DD, Goel N, Gossec L, Hoejgaard P, Leung YY, Lindsay C, Strand V, van der Heijde DM, Shea B, Christensen R, Coates L, Eder L, McHugh N, Kalyoncu U, Steinkoenig I, Ogdie. A Updating the Psoriatic Arthritis (PsA) Core Domain Set: A Report from the PsA Workshop at OMERACT 2016. J Rheumatol. 2017 Oct;44(10):1522-1528

5. Holland R, Tillett W, Korendowych E, Cavill C, Waldron N, Brooke M, McHugh NJ. Validation of the Psoriatic Arthritis Impact of Disease (PsAID) Questionnaire and its potential as a single-item outcome measure in clinical practice. Ann.Rheum.Dis. 2018;77(3):343-347.

6. Gossec L, de WM, Kiltz U, Braun J, Kalyoncu U, Scrivo R, Maccarone M, Carton L, Otsa K, Sooaar I, Heiberg T, Bertheussen H, Canete JD, Sanchez LA, Balanescu A, Dinte A, de VK, Smolen JS, Stamm T, Niedermayer D, Bekes G, Veale D, Helliwell P, Parkinson A, Luger T, Kvien TK. A patient-derived and patient-reported outcome measure for assessing psoriatic arthritis: elaboration and preliminary validation of the Psoriatic Arthritis Impact of Disease (PSAID) questionnaire, a 13-country EULAR initiative. Ann.Rheum.Dis. 2014;73(6):1012-1019.

7. Kirwan JR, Bartlett SJ, Beaton DE, Boers M, Bosworth A, Brooks PM, Choy E, de WM, Guillemin F, Hewlett S, Kvien TK, Landewe RB, Leong AL, Lyddiatt A, March L, May J, Montie PL, Nikai E, Richards P, Voshaar MM, Smeets W, Strand V, Tugwell P, Gossec L. Updating the OMERACT filter: implications for patient-reported outcomes. J.Rheumatol. 2014;41(5):1011-1015.

8. Studenic P, Radner H, Smolen JS, Aletaha D. Discrepancies between patients and physicians in their perceptions of rheumatoid arthritis disease activity. Arthritis Rheum. 2012;64(9):2814-2823. 
9. Webber K, Davies AN, Cowie MR. Disparities Between Clinician and Patient Perception of Breakthrough Pain Control. J.Pain Symptom.Manage. 2016;51(5):933-937.

10. Desthieux C, Granger B, Balanescu AR, Balint P, Braun J, Canete JD, Heiberg T, Helliwell PS, Kalyoncu U, Kvien TK, Kiltz U, Niedermayer D, Otsa K, Scrivo R, Smolen J, Stamm TA, Veale DJ, de VK, de WM, Gossec L. Determinants of Patient-Physician Discordance in Global Assessment in Psoriatic Arthritis: A Multicenter European Study. Arthritis Care Res.(Hoboken.) 2017;69(10):1606-1611.

11. Queiro R, Cañete JD, Montilla C, Abad M, Montoro M, Gomez S, Cabez A. Minimal disease activity and impact of disease in psoriatic arthritis: a Spanish cross-sectional multicenter study. Arthritis Res.Ther. 2017;19(1):72.

12. Taylor W, Gladman D, Helliwell P, Marchesoni A, Mease P, Mielants H. Classification criteria for psoriatic arthritis: development of new criteria from a large international study. Arthritis Rheum. 2006;54(8):2665-2673.

13. Coates LC, Fransen J, Helliwell PS. Defining minimal disease activity in psoriatic arthritis: a proposed objective target for treatment. Ann.Rheum.Dis. 2010;69(1):48-53.

14. Schoels MM, Aletaha D, Alasti F, Smolen JS. Disease activity in psoriatic arthritis (PsA): defining remission and treatment success using the DAPSA score. Ann.Rheum.Dis. 2016;75(5):811-818.

15. Hojgaard P, Klokker L, Orbai AM, Holmsted K, Bartels EM, Leung YY, Goel N, de WM, Gladman DD, Mease P, Dreyer L, Kristensen LE, FitzGerald O, Tillett W, Gossec L, Helliwell P, Strand V, Ogdie A, Terwee CB, Christensen R. A systematic review of measurement properties of patient reported outcome measures in psoriatic arthritis: A GRAPPA-OMERACT initiative. Semin.Arthritis Rheum. 2018;47(5):654-665.

16. Gorlier C, Orbai AM, Puyraimond-Zemmour D, Coates LC, Kiltz U, Leung YY, Palominos P, Canete JD, Scrivo R, Balanescu A, Dernis E, Talli S, Ruyssen-Witrand A, Soubrier M, Aydin SZ, Eder L, Gaydukova I, Lubrano E, Kalyoncu U, Richette P, Husni ME, de WM, Smolen JS, Gossec L. Comparing patientperceived and physician-perceived remission and low disease activity in psoriatic arthritis: an analysis of 410 patients from 14 countries. Ann.Rheum.Dis. 2019;78(2):201-208.

17. Queiro R. Remission and stringent treatment goals in psoriatic arthritis: Doctors' opinion is not enough. Joint Bone Spine 2019;86(2):269-270.

18. van Mens LJJ, Turina MC, van de Sande MGH, Nurmohamed MT, van Kuijk AWR, Baeten DLP. Residual disease activity in psoriatic arthritis: discordance between the rheumatologist's opinion and minimal disease activity measurement. Rheumatology.(Oxford) 2018;57(2):283-290.

19. Smolen JS, Schols M, Braun J, Dougados M, FitzGerald O, Gladman DD, Kavanaugh A, Landewe R, Mease P, Sieper J, Stamm T, Wit M, Aletaha D, Baraliakos X, Betteridge N, Bosch FVD, Coates LC, Emery P, Gensler LS, Gossec L, Helliwell P, Jongkees M, Kvien TK, Inman RD, Mclnnes IB, Maccarone M, Machado PM, Molto A, Ogdie A, Poddubnyy D, Ritchlin C, Rudwaleit M, Tanew A, Thio B, Veale D, Vlam K, van der Heijde D. Treating axial spondyloarthritis and peripheral spondyloarthritis, especially psoriatic arthritis, to target: 2017 update of recommendations by an international task force. Ann.Rheum.Dis. 2018;77(1):3-17. 
20. Ritchlin CT, Colbert RA, Gladman DD. Psoriatic Arthritis. N.Engl.J.Med. 2017;376(10):957-970.

21. Bakirci S, Solmaz D, Al Osaimi N, Dalkilic E, Can M, Erden A, Ozisler C, Cinar M, Kilic L, Kucuk A, Omma A, Yildiz F, Dogru A, Tufan A, Esmen SE, Akar S, Kalyoncu U, Aydin SZ, PsArt-ID (Psoriatic Arthritis-International Database). What are the main barriers to achieve minimal disease activity in psoriatic arthritis in real life? Clin.Exp.Rheumatol. 2019;37(5):808-812.

22. Gladman DD, Farewell VT. The role of HLA antigens as indicators of disease progression in psoriatic arthritis. Multivariate relative risk model. Arthritis Rheum. 1995;38(6):845-850.

23. Husted JA, Tom BD, Farewell VT, Schentag CT, Gladman DD. A longitudinal study of the effect of disease activity and clinical damage on physical function over the course of psoriatic arthritis: Does the effect change over time? Arthritis Rheum. 2007;56(3):840-849.

24. Orbai AM, Perin J, Gorlier C, Coates LC, Kiltz U, Leung YY, Palominos PE, Canete JD, Scrivo R, Balanescu A, Dernis E, Talli S, Ruyssen-Witrand A, Soubrier M, Aydin S, Eder L, Gaydukova I, Lubrano E, Kalyoncu U, Richette P, Husni ME, Smolen JS, de WM, Gossec L. Determinants of Patient-Reported Psoriatic Arthritis Impact of Disease: An Analysis of the Association with Gender in 458 Patients from 14 Countries. Arthritis Care Res.(Hoboken.) 2019.

25. Galĺndez E, Carmona L. Is obesity in psoriatic arthritis associated with a poorer therapeutic response and more adverse effects of treatment with an anchor drug? Reumatol.Clin. 2016;12(6):307-312.

26. Queiro R, Cañete JD. Impact of cardiovascular risk factors on the achievement of therapeutic goals in psoriatic arthritis: is there any association? Clin.Rheumatol. 2018;37(3):661-666. 